\title{
Terminal Oxidase of Crithidia fasciculata. Reactions with Carbon Monoxide and Oxygen at Subzero Temperatures and Photochemical Action Spectra
}

\author{
By ROBERT I. SCOTT, ${ }^{*}{ }^{*}$ STEVEN W. EDWARDS,${ }^{1} \dagger$ BRITTON CHANCE ${ }^{2}$ \\ AND DAVID LLOYD ${ }^{1}$ \\ ${ }^{1}$ Department of Microbiology, University College, Newport Road, Cardiff CF2 ITA, U.K. \\ ${ }^{2}$ Johnson Research Foundation, School of Medicine, University of Pennsylvania, \\ Philadelphia PA 19174 U.S.A.
}

(Received 24 January 1983)

\begin{abstract}
Room temperature CO-difference spectra of whole cells of Crithidia fasciculata show two COreacting haemoproteins. The reaction of cytochrome $a / a_{3}$ with $\mathrm{CO}$ is complete within $1 \mathrm{~min}$ of bubbling with $\mathrm{CO}$; that of cytochrome $b$ takes longer than $40 \mathrm{~min}$. A non-photodissociable $\mathrm{O}_{2}$ containing compound of cytochrome $a / a_{3}$ was formed in whole cell suspensions at $-112{ }^{\circ} \mathrm{C}$ after photolysis of $\mathrm{CO}$ in the presence of $200 \mu \mathrm{M}-\mathrm{O}_{2}$. No $\mathrm{O}_{2}$-cytochrome $b$ compound was observed under these conditions. Photochemical action spectra for the relief of $\mathrm{CO}$-inhibited respiration, obtained at different $\mathrm{O}_{2}$ tensions, indicate cytochrome $a / a_{3}$ to be the major haemoprotein terminal oxidase; no evidence for a $b$-type cytochrome oxidase has been found.
\end{abstract}

\section{INTRODUCTION}

The trypanosomatid Crithidia fasciculata contains $a$-, $b$ - and $c$-type cytochromes (Hill \& Anderson, 1970; Hill \& White, 1968a, $b$; Edwards \& Lloyd, 1973) together with a pigment having absorbance maxima at 419,540 and $570 \mathrm{~nm}$ in CO-difference spectra and designated 'cytochrome $o$ ' (Hill \& White, 1968b). A partial purification of this CO-binding pigment has been made (Hill \& Cross, 1973). Evidence for the presence of cytochrome $o$ (from CO-difference spectra) in Crithidia oncopelti (Srivastava, 1971) and other Kinetoplastidae (Hill \& Cross, 1973) has been presented. Respiratory inhibitors have been used to show routes of electron transport alternative to the main respiratory chain in C. fasciculata (Hill \& Cross, 1973; Edwards \& Lloyd, 1973), although the nature of the alternative oxidase(s) is not known. A biphasic cyanide inhibition titration indicated the presence of two oxidases in C. oncopelti (Edwards \& Chance, 1982). Proof of the presence, and functional activity, of cytochrome $o$ in eukaryotes would be of evolutionary significance since cytochrome $o$ has not been convincingly demonstrated to be a functional oxidase in unicellular or multicellular eukaryotes (Kusel \& Storey, 1973).

A direct method for demonstrating the existence and functionality of CO-binding haemoprotein terminal oxidases, first devised by Warburg \& Negelein (1928), is the determination of the photochemical action spectrum for $\mathrm{CO}$ dissociation. All known haemoproteins which bind or react with $\mathrm{O}_{2}$ in the ferrous form also bind $\mathrm{CO}$ in this form and are photodissociable. Evidence for the functional activity of cytochrome $o$ in Trypanosoma mega, Blastocrithidia culicis and Leishmania tarentolae from photochemical action spectra has been claimed (Kronick \& Hill, 1974); evidence for cytochrome $o$ from photochemical action spectra was not found in C. oncopelti. However, a more recent study by Edwards \& Chance (1982), using

† Present address: Department of Medical Biochemistry, University of Wales Hospital, Heath Park, Cardiff CF4 4XY, U.K. 
a liquid dye laser instead of a conventional monochromator, showed cytochrome $o$ activity in this organism.

Evidence for cytochrome $o$ activity in $C$. fasciculata has been presented by Kusel \& Kronick (1972) who found a 'shoulder' in the action spectrum at $415-420 \mathrm{~nm}$, corresponding to the cytochrome $o-\mathrm{CO}$ complex. A component with a maximum at $570 \mathrm{~nm}$ in the photochemical action spectrum was observed by Edwards \& Lloyd (1973) but no corresponding maximum in the Soret region of the action spectrum was found, leading to the conclusion that cytochrome $o$ was not present. The action spectra obtained by Kusel \& Storey (1973) led these investigators to a similar conclusion.

In an attempt to resolve the question of the presence and activity of cytochrome $o$ in $C$. fasciculata we have re-examined the $\mathrm{CO}$ - and $\mathrm{O}_{2}$-binding properties of haemoproteins in this organism. CO-difference spectra reveal the presence of a $b$-type cytochrome that binds $\mathrm{CO}$ slowly. Low-temperature photodissociation spectra show only one $\mathrm{O}_{2}$-containing intermediate (i.e. that of cytochrome $a / a_{3}$ ) and photochemical action spectra at different $\mathrm{O}_{2}$ tensions using a liquid dye laser indicate only cytochrome $a / a_{3}$ as terminal oxidase. We conclude that cytochrome $o$ does not act as a terminal oxidase in this organism, and that any alternative oxidases are not haemoproteins.

\section{METHODS}

Growth and harvesting of the organism. Crithidia fasciculata was grown in a medium which contained $2 \%(\mathrm{w} / \mathrm{v})$ proteose peptone, $0 \cdot 1 \%$ liver digest, $1 \%(\mathrm{w} / \mathrm{v})$ glycerol, $0.5 \%$ Tween $80,0.6 \%$ triethanolamine, $25 \mathrm{mg}$ haemin $1^{-1}$ and $2.5 \mathrm{mg}$ folic acid $\mathrm{l}^{-1}$, as described by Edwards \& Lloyd (1973). Harvesting of cells in the late exponential phase of growth was by centrifugation at $1500 \mathrm{~g}\left(r_{\mathrm{av}} .7 .0 \mathrm{~cm}\right)$ at room temperature in the $8 \times 50 \mathrm{ml}$ rotor of a Sorvall RC$5 \mathrm{~B}$ centrifuge.

Cytochrome spectra. Difference spectra were measured using a Hitachi/Perkin-Elmer 557 spectrophotometer (Lloyd et al., 1982, Scott \& Lloyd, 1983). Cells were harvested, washed twice in $20 \mathrm{~mm}$-potassium phosphate buffer (pH 8.0) and resuspended in $6 \mathrm{ml} 20 \mathrm{~mm}$-phosphate buffer $(\mathrm{pH} 8.0)$ containing $0.5 \%$ methyl cellulose. Spectra were recorded at room temperature in cuvettes of $10 \mathrm{~mm}$ path-length; spectral band-width was $2 \mathrm{~nm}$ and the scanning speed $60 \mathrm{~nm} \mathrm{~min}{ }^{-1}$. CO was bubbled for $30 \mathrm{~s}$ into open cuvettes which were scanned at various times after the addition of $\mathrm{CO}$.

Low-temperature flash photolysis. The technique used was that of Chance et al. $(1975 a)$. Washed whole-cell suspensions of $C$. fasciculata were incubated in $30 \%(\mathrm{v} / \mathrm{v})$ ethylene glycol for $5 \mathrm{~min}$ in $3 \mathrm{~mm}$ path-length cuvettes at room temperature; endogenous respiration ensured anaerobiosis. Cuvettes were bubbled with $\mathrm{CO}$ for $2 \mathrm{~min}$, incubated at room temperature for a further $2 \mathrm{~min}$, cooled to $-20{ }^{\circ} \mathrm{C}$ and equilibrated in the dark for $5 \mathrm{~min}$. Some suspensions were then oxygenated (Chance et al., 1975 b) by vigorous stirring; cuvettes were then transferred to a bath containing ethanol and solid $\mathrm{CO}_{2}$ at $-80^{\circ} \mathrm{C}$ in the dark. Analyses were performed in a dual-wavelength spectrophotometer; baseline corrections (spectra of CO-liganded anaerobic cell suspensions) were stored in a digital memory. The cuvette was cooled by a stream of cold $\mathrm{N}_{2}$ gas to the required temperature. Flash photolysis by a $20 \mathrm{~J}$ xenon lamp was followed by repetitive scanning at $90 \mathrm{~s}$ intervals. Further details are provided by Lloyd et al. (1982).

Photochemical action spectra. Reversal by light of $\mathrm{CO}$ inhibition of respiration was obtained using a liquid dye laser excited by an $8 \mathrm{~W}$ argon ion laser. Rhodamine $6 \mathrm{G}$ was used to obtain laser light over the range $568-630 \mathrm{~nm}$ and Rhodamine 110 over the range 533-568 nm (Lloyd et al., 1982; Lloyd \& Scott, 1983). The power of laser light used for illumination was kept constant for each wavelength used by altering the power of the input argon ion laser. Measurements of the respiration of whole-cell suspensions were made at $30^{\circ} \mathrm{C}$ with an open reaction system ( $5 \mathrm{ml}$ working volume) fitted with an oxygen electrode (Radiometer, Copenhagen, Denmark) and stirred at 1500 r.p.m. Either a $\mathrm{CO} / \mathrm{O}_{2}$ or $\mathrm{CO} /$ air $(19: 1, \mathrm{v} / \mathrm{v})$ gas mixture flowed over the vortex of the cell suspension. Full details of the method are presented elsewhere (Lloyd \& Scott, 1983).

\section{RESULTS}

\section{Room-temperature $\mathrm{CO}$-difference spectra}

Room-temperature CO-difference spectra of washed whole-cells of $C$. fasciculata are shown in Fig. 1. The first scan, 1 min after bubbling with CO (Fig. $1 a, b$ ), shows in the $\alpha$-region a maximum at $590 \mathrm{~nm}$ (assigned to the cytochrome $a_{3}-\mathrm{CO}$ complex) and a shoulder at $570 \mathrm{~nm}$ (due to a cytochrome $b-\mathrm{CO}$ complex); a minimum at $558 \mathrm{~nm}$ was observed. The $\gamma$-region shows a 


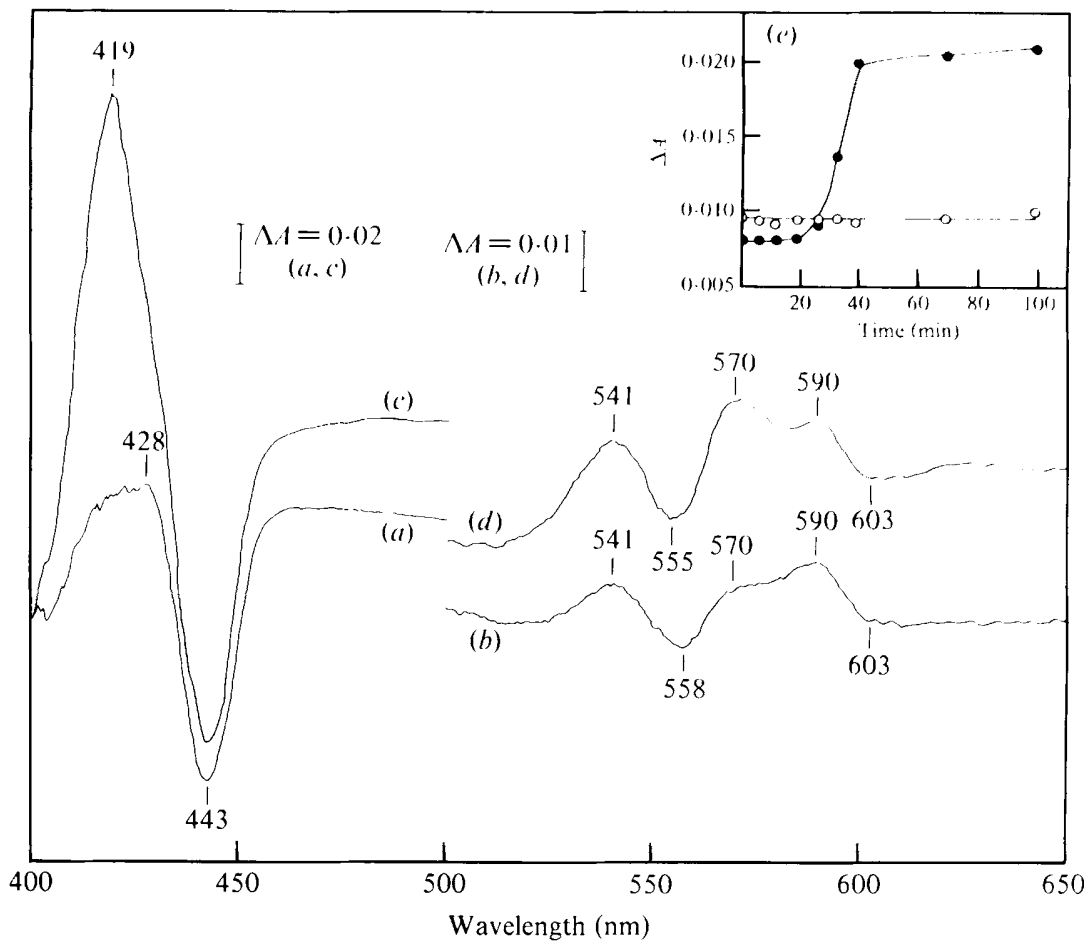

Fig. 1. Room-temperature CO-difference spectra of $C$. fasciculata and the kinetics of reaction with CO. Harvested, washed cells were resuspended in $20 \mathrm{~mm}$-phosphate buffer ( $\mathrm{pH} 8.0)$ containing $0.5 \%$ methyl cellulose and allowed to become anaerobic in the presence of $50 \mathrm{~mm}$-glycerol. A reduced minus reduced baseline (not shown) was recorded and the sample cuvette bubbled with CO for $30 \mathrm{~s}$. Spectra $(a)$ and $(b)$ were recorded $1 \mathrm{~min}$ after the addition of $\mathrm{CO} ;(c)$ and $(d)$ were recorded $68 \mathrm{~min}$ later. In $(e)$ the absorbance changes at $570-558 \mathrm{~nm}(O)$ and $590-603 \mathrm{~nm}(O)$ are plotted as a function of time after bubbling with $C O$. The scan speed was $60 \mathrm{~nm} \mathrm{~min}-1$, slit width $2 \mathrm{~nm}$, path-length $1 \mathrm{~cm}$ and the protein content was $32 \cdot 4 \mathrm{mg} \mathrm{ml}^{-1}$.

broad asymmetric peak with a maximum at $428 \mathrm{~nm}$. A further scan, obtained after a further $68 \mathrm{~min}$ (Fig. $1 c, d$ ) shows a maximum at $590 \mathrm{~nm}$; the intensity of the $570 \mathrm{~nm}$ component is increased and the associated trough has shifted from 558 to $555 \mathrm{~nm}$. The peak in the $\gamma$-region of the spectrum is increased in intensity and shifted from 428 to $419 \mathrm{~nm}$, and is assigned to the formation of a cytochrome $b-\mathrm{CO}$ complex; the cytochrome $a / a_{3}-\mathrm{CO}$ complex is no longer clearly visible. The kinetics of the formation of the $\mathrm{CO}$ complexes of cytochrome $a / a_{3}$ and cytochrome $b$ are shown in Fig. $1(e)$. The reaction of cytochrome $a / a_{3}$ with $\mathrm{CO}$ is complete within $1 \mathrm{~min}$, indicated by the constant $\Delta A(590-603 \mathrm{~nm})$. The cytochrome $b-C O$ complex takes longer to form; the reaction is virtually complete after $40 \mathrm{~min}$.

\section{Low-temperature photodissociation spectra}

Photodissociation spectra of whole cells of $C$. fasciculata after treatment with $\mathrm{CO}$ for $2 \mathrm{~min}$ are shown in Fig. 2 and indicate the presence of more than one CO-reacting haemoprotein. The first scan after photolysis (i.e. flash-photolysed minus CO-reduced) is shown. The minima at 595 and $435 \mathrm{~nm}$ are due to the CO-liganded forms of cytochrome $a_{3}$; the maximum at $449 \mathrm{~nm}$ is due to the appearance of the reduced form. Photolysis also yielded components with maxima at 428 and $564 \mathrm{~nm}$, due to the reduced form of $b$-type cytochrome. Repeated scans (not shown) indicated that the recombination of cytochrome $a_{3}$ with $\mathrm{CO}$ at this temperature was hardly detectable over $15 \mathrm{~min}$ and hardly any photolytic dissociation was obtained by a further flash after 11 scans. Photolysis in the presence of $200 \mu \mathrm{M}-\mathrm{O}_{2}$ at $-112^{\circ} \mathrm{C}$ (Fig. 3) and successive 


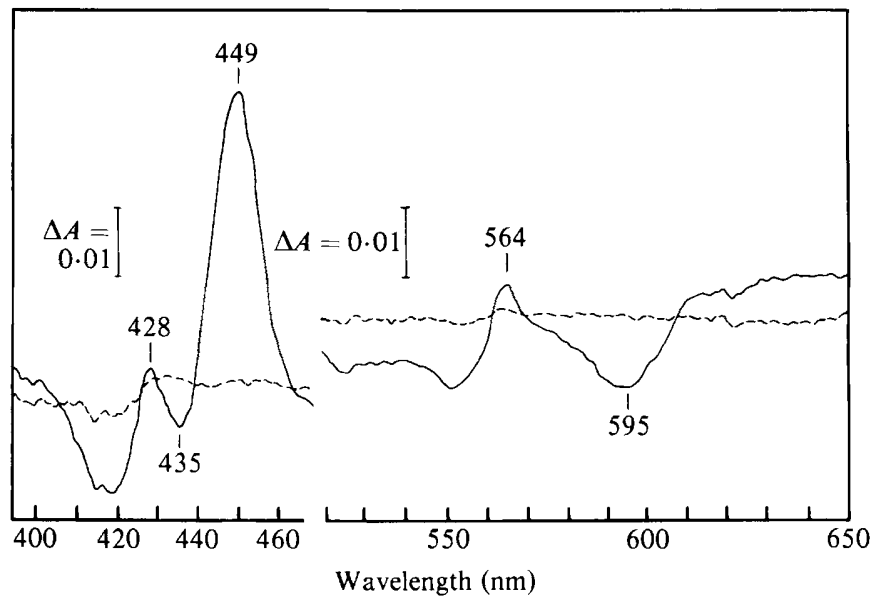

Fig. 2. The reaction of haemoproteins of $C$. fasciculata with $\mathrm{CO}$ at $-112^{\circ} \mathrm{C}$. The spectrum of $\mathrm{CO}-$ liganded endogenously reduced cells was scanned and stored in the digital memory of a dual-wavelength spectrophotometer. The first scan yielded the baseline (----) and represents a $\mathrm{CO}$-reduced minus $\mathrm{CO}-$ reduced spectrum. The next scan (-) followed photolysis at $-112^{\circ} \mathrm{C}$ using three flashes. Scanning was from right to left at $3.5 \mathrm{~nm} \mathrm{~s}^{-1}$ and the reference wavelength was $575 \mathrm{~nm}$. Absorbance increments and the wavelengths (in $\mathrm{nm}$ ) of distinctive spectral features are shown.

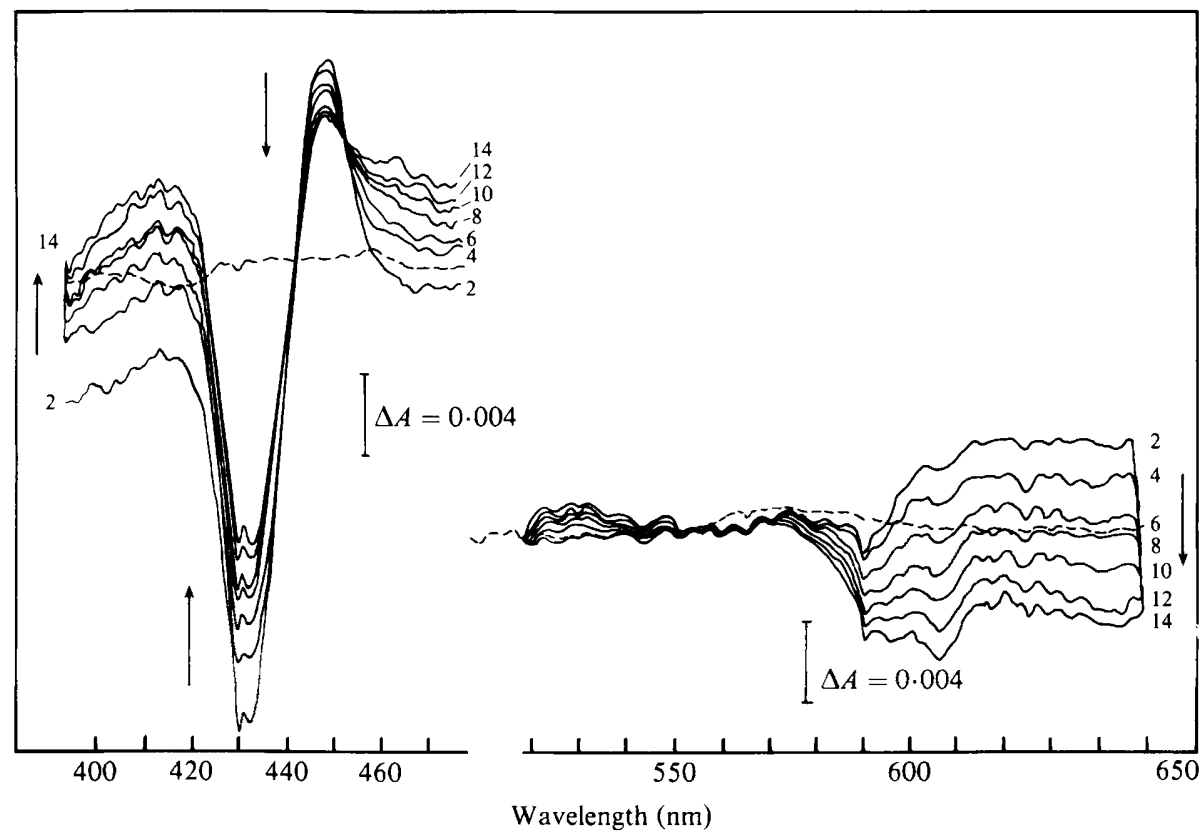

Fig. 3. The reaction of haemoproteins of $C$. fasciculata with $\mathrm{O}_{2}$ at $-112^{\circ} \mathrm{C}$. The spectrum of a suspension of CO-liganded, endogenously reduced (anaerobic) organisms into which $\mathrm{O}_{2}$ had been stirred at $-20^{\circ} \mathrm{C}$ was scanned at $-112^{\circ} \mathrm{C}$ and the spectrum stored in the memory of a dual-wavelength spectrophotometer. The reference wavelength was $575 \mathrm{~nm}$. Subsequent scans are difference spectra with the stored spectrum subtracted. The dashed line is the CO-reduced minus CO-reduced baseline, recorded before initiation of the reaction by three flashes. Subsequent spectra were recorded at $90 \mathrm{~s}$ intervals; alternate spectra are shown.

scanning indicated the formation of an $\mathrm{O}_{2}$-containing intermediate of cytochrome $a_{3}$ which was spectrally distinct from the CO-liganded oxidase. This $\mathrm{O}_{2}$-containing complex was not photodissociable by light intensities giving photolysis of the CO-liganded oxidase (results not shown). No $\mathrm{O}_{2}$-containing complex of a $b$-type cytochrome was detectable at this temperature. 


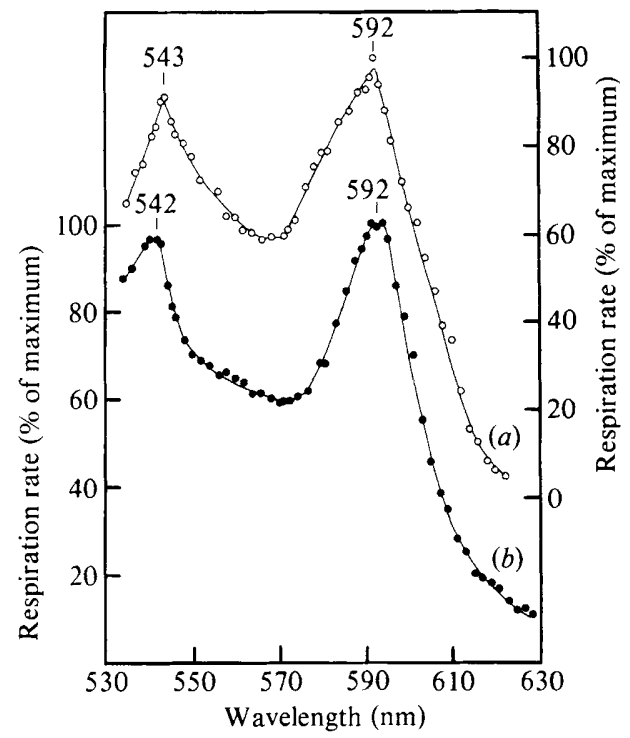

Fig. 4. Photochemical action spectra of $C$. fasciculata. Cells were harvested, concentrated 10-fold and resuspended in growth medium. The gas phase passing over the cell suspension in $(a)$ contained $\mathrm{CO} /$ air $(95: 5, \mathrm{v} / \mathrm{v})$, and in $(b)$ it contained $\mathrm{CO} / \mathrm{O}_{2}(95: 5, \mathrm{v} / \mathrm{v})$, giving $\mathrm{O}_{2}$ concentrations in the liquid phase of 7.5 and $43.6 \mu \mathrm{M}$, respectively. Laser powers used to illuminate the cell suspensions for Rhodamine $6 \mathrm{G}$ were $25 \mathrm{~mW}$ and for Rhodamine $11040 \mathrm{~mW}$. Spectra obtained with Rhodamine $110(535-568 \mathrm{~nm})$ were normalized to those of Rhodamine $6 \mathrm{G}(568-630 \mathrm{~nm})$ by assuming the rates obtained at $568 \mathrm{~nm}$ with the two dyes to be equal and expressing rates as a function of the maximum rate obtained.

\section{Photochemical action spectra}

In order to determine whether the slowly CO-reacting $b$-type pigment observed in difference spectra (Fig. 1) acted as a functional terminal oxidase, photochemical action spectra for the release of CO-inhibited respiration using a liquid dye laser (Lloyd \& Scott, 1983) were obtained. Rhodamine 110 was used for laser light from $533-568 \mathrm{~nm}$ and Rhodamine $6 \mathrm{G}$ from $568-630 \mathrm{~nm}$. The action spectrum of $C$. fasciculata obtained under a gas phase of $\mathrm{CO} /$ air $(95: 5, \mathrm{v} / \mathrm{v})\left(\mathrm{O}_{2}\right.$ concn in the liquid $=7.5 \mu \mathrm{M}$ ) shows maxima at 592 and $543 \mathrm{~nm}$ corresponding to the $\alpha$-and $\beta$-bands, respectively, of the CO-liganded form of cytochrome $a_{3}$ (Fig. $4 a$ ). When a gas phase of $\mathrm{CO} / \mathrm{O}_{2}$ $(95: 5, \mathrm{v} / \mathrm{v})\left(\mathrm{O}_{2}\right.$ concn $\left.43.6 \mu \mathrm{M}\right)$ was employed (Fig. $\left.4 b\right)$, similar maxima were obtained, indicating the presence of a single oxidase. No evidence for cytochrome $o$ activity (indicated by a maximum at about $570 \mathrm{~nm}$ ) was found in either action spectrum.

\section{DISCUSSION}

The present paper confirms the role of cytochrome $a / a_{3}$ as the major haemoprotein terminal oxidase in $C$. fasciculata. The CO-binding $b$-type cytochrome, present in intact cells and previously referred to as cytochrome $o$ does not function as an oxidase. Other slowly CO-reacting $b$-type cytochromes that do not act as oxidases have been found in Acanthamoeba castellanii (Scott \& Lloyd, 1983) and Tetrahymena pyriformis (Lloyd et al., 1982). The time-course of the slow formation of the cytochrome $b-\mathrm{CO}$ complex in $C$. fasciculata (Fig. $1 e$ ) is different from the monotonic increase observed in $A$. castellanii (Scott \& Lloyd, 1983) and may be due to the presence of ingested haemin, or to two or more haemoproteins that differ in their rates of reaction with $\mathrm{CO}$. Other components that yield $\mathrm{CO}$-difference spectra and resemble cytochrome $o$ have been suggested by Edwards \& Lloyd (1973) and include crithidial haemoglobin, a degradation product of cytochrome $\mathbf{P}_{450}$ or cytochrome $b$, and cytochrome $c$ peroxidase. 
Low-temperature photodissociation spectra also indicate the presence of two CO-binding haemoproteins, but only one of these (cytochrome $a_{3}$ ) reacts to form an $\mathrm{O}_{2}$-containing intermediate. The presence of more than one photodissociable CO-binding haemoprotein has been shown in Tetrahymena pyriformis, although cytochrome $a_{620}$ is the sole haemoprotein oxidase (Lloyd et al., 1982). Acanthamoeba castellanii has four $\mathrm{CO}-$ (and $\mathrm{O}_{2}^{-}$) binding haemoproteins (Lloyd et al., 1981) but only one of these (cytochrome $a_{3}$ ) acts as an oxidase (Scott \& Lloyd, 1983).

The action spectra obtained by Kronick \& Hill (1974) failed to reveal cytochrome $o$ in $C$. oncopelti, although this oxidase was detected by Edwards \& Chance (1982) using high lightintensities from a liquid dye laser. The action spectra in the present paper are different from the action spectrum of $C$. oncopelti (Edwards \& Chance, 1982) where a maximum at $576 \mathrm{~nm}$ was clearly visible. The cellular location of this cytochrome oxidase is unknown and may be associated with the bacterial endosymbiont known to be present (Edwards \& Chance, 1982). Action spectra of $C$. fasciculata obtained at different $\mathrm{O}_{2}$ tensions failed to reveal cytochrome $o$; this oxidase has been detected in Leishmania tarentolae, although only at lowered $\mathrm{O}_{2}$ concentrations (Kronick \& Hill, 1974).

Previously, action spectra of $C$. fasciculata have revealed the presence of cytochrome $o$ (Kusel \& Kronick, 1972), although this finding was refuted by Kusel \& Storey (1973) who could find no cytochrome $o$ activity even after growth of cells in the presence of acriflavin, or after obtaining the action spectrum in the presence of antimycin or azide. Edwards \& Lloyd (1973) found a component in the action spectrum at $570 \mathrm{~nm}$ but with no corresponding maximum in the Soret region. All of these studies used light from conventional monochromators of relatively broad band-width, did not correct for energy content through the spectrum and used the 'hanging drop' method. All of these factors in determining the action spectrum may be criticized (Lloyd \& Scott, 1983) and may have contributed to the different results so far obtained. The use of a liquid dye laser and a stirred cell suspension (Lloyd \& Scott, 1983) eliminate these problems. Our findings, that the $b$-type cytochrome present in $C$. fasciculata reacts slowly with $C O$ in difference spectra, does not form an $\mathrm{O}_{2}$-containing intermediate in photodissociation spectra and does not contribute to the photochemical action spectrum, strongly indicate that it does not function as an oxidase.

This work was completed during tenure (by S.W.E.) of a University of Wales Postdoctoral Fellowship and a Royal Society Travel Grant. The Royal Society and the Science and Engineering Research Council are thanked for generous financial support.

\section{REFERENCES}

Chance, B., Saronio, C. \& Leigh, J. S. (1975a). Functional intermediates in the reaction of membranebound cytochrome oxidase with oxygen. Journal of Biological Chemistry 250, 9226-9237.

Chance, B., Graham, N. \& Legallais, V. (1975b). Low temperature trapping method for cytochrome oxidase oxygen intermediates. Analytical Biochemistry 67, 552-579.

Edwards, C. \& Chance, B. (1982). Evidence for the presence of two terminal oxidases in the trypanosomatid Crithidia oncopelti. Journal of General Microbiology 128, 1409-1414.

Edwards, C. \& Lloyd, D. (1973). Terminal oxidases and carbon monoxide-reacting haemoproteins in the trypanosomatid Crithidia fasciculata. Journal of General Microbiology 79, 275-284.

Hill, G. C. \& Anderson, W. A. (1970). Electron transport systems and mitochondrial DNA in Trypanosomatidae: a review. Experimental Parasitology 28, 356-380.
Hill, G. C. \& Cross, G. A. M. (1973). Cyanideresistant respiration and a branched cytochrome system in Kinetoplastidae. Biochimica et biophysica acta 305, 590-596.

Hill, G. C. \& White, D. C. (1968a). Characterization of the cytochrome system in Crithidia fasciculata. Bacteriological Proceedings 68, 138-139.

Hill, G. C. \& White, D. C. (1968b). Respiratory pigments of Crithidia fasciculata. Journal of Bacteriology 95, 2151-2157.

KRONICK, P. \& HILL, G. C. (1974). Evidence for the functioning of cytochrome $o$ in Kinetoplastida. Biochimica et biophysica acta 368, 173-180.

Kusel, J. P. \& Kronick, P. (1972). The function of cytochrome $o$ in the trypanosomatid hemoflagellate, Crithidia fasciculata. Federation Proceedings 31, 878.

Kusel, J. P. \& Storey, B. T. (1973). CO-binding pigments and the functional terminal oxidase of the trypanosomatid hemoflagellate Crithidia fasciculata. Biochimica et biophysica acta 314, 164-177. 
LLOYD, D. \& ScotT, R. I. (1983). Photochemical action spectra of CO-liganded terminal oxidases using a liquid dye laser. Analytical Biochemistry 128, 21-25.

Lloyd, D., Edwards, S. W. \& Chance, B. (1981). Carbon monoxide and oxygen-reacting haemoproteins in the mitochondrial fraction from the soil amoeba Acanthamoeba castellanii. Studies at subzero temperatures. Biochemical Journal 200, 337-342.

Lloyd, D., SCOTt, R. I., Edwards, S. W., EdWards, C. \& CHANCE, B. (1982). Cytochrome $a_{620}$ in Tetrahymena pyriformis. Reactions with carbon monoxide and oxygen at subzero temperatures and photochemical action spectra. Biochemical Journal 206, 367-372.
SCOTT, R. I. \& LLOYD, D. (1983). Photochemical action spectra indicate that cytochrome $a / a_{3}$ is the predominant haemoprotein terminal oxidase in Acanthamoeba castellanii. Biochemical Journal 210, 721725.

Srivastava, H. K. (1971). Carbon monoxide-reactive haemoproteins in parasitic flagellate Crithidia oncopelti. FEBS Letters 16, 189-191.

WARBURG, D. \& Negelein, E. (1928). Über die photochemische Dissoziation bei intermittierender Belichtung und das absolute Absorptionsspektrum des Atmungsferments. Biochemische Zeitschrift 202, 202-208. 